будь-яких форм фізичного та психологічного насильства, приниження честі та гідності, дискримінації за будь-якою ознакою; заборону пропаганди та агітації, що завдає шкоди здоров'ю здобувачів освіти; заборону вживання на території закладів освіти алкогольних напоїв, наркотичних засобів, тютюнових виробів, інших шкідливих речовин.

Асистент учня(дитини) не здійснює: втручання в освітній процес; виконання освітньої програми для досягнення учнями результатів навчання; надання освітніх послуг в закладі освіти; надання рекомендацій педагогічним працівникам щодо організації освітнього процесу; розробку індивідуальних завдань і матеріалів для учнів із особливими освітніми потребами; виконання інших функцій педагогічних працівників. Асистент учня забезпечує соціально-побутові потреби учня з особливими освітніми потребами, для чого може бути присутній (за згодою керівника закладу освіти) під час уроків та позакласної роботи, інших заходів закладу освіти, допомагати у пересуванні, відвідуванні туалету, переодяганні, харчуванні та задоволенні інших соціальних та фізичних потреб здобувача освіти.

Асистент учня (дитини) відповідно до Примірного положення про команду супроводу залучається до складу команди супроводу дитини та має сприяти досягненню визначених командою супроводу цілей розвитку у питаннях соціальної адаптації, комунікації та соціально-побутової орієнтації. Наголошуємо, що асистент вчителя та асистент учня (дитини) виконують різні функції та мають різні обов'язки. Асистент дитини працює з однією чи кількома дітьми, а асистент вчителя - 3 усім класом [1].

Рекомендовано інформувати учасників освітнього процесу, у т.ч. батьків (інших законних представників) дитини про функції асистента вчителя та асистента учня, можливості отримання послуги супроводу під час інклюзивного навчання в установах соціального захисту населення [3].

Висновки. Супровід учня (дитини) під час інклюзивного навчання - одна 3 базових соціальних послуг. Метою іiї впровадження є забезпечення повної та ефективної участі дітей з особливими освітніми потребами в освітньому процесі. Отже, запровадження Державного стандарту супроводу під час інклюзивного навчання необхідно запровадити у найближчий час.

Ключові слова: асистент учня (дитини), інклюзивна освіта, учасники освітнього процесу, соціальна послуга.

\title{
Лiтература
}

1. Державний стандарт супроводу під час інклюзивного навчання (проект) [Електронний ресурс] / Офіційний сайт Мінсоцполітики України. - Режим доступу: https://www.msp.gov.ua/projects/516.

2. Закон України «Про повну загальну середню освіту [Електронний ресурс] / Офіційний сайт Верховної Ради України. - Режим доступу: https://zakon.rada.gov.ua/laws/show/463-20\#Text.

3. Щодо організації навчання осіб з особливими освітніми потребами у закладах загальної середньої освіти у 2020/2021 навчальному році [Електронний ресурс] / Офіційний сайт МОН України. - Режим доступу: https://mon.gov.ua/ ua/npa/shodo-organizaciyi-navchannya-osib-z-osoblivimi-osvitnimi-potrebami-u-zakladah-zagalnoyi-serednoyi-osviti-u20202021-navchalnomu-roci.

Мавлянова З.Ф.

\section{Нутритивный анамнез и толщина кожно-жировых складок как предикторы нутритивной недостаточности у детей с церебральным параличом}

\author{
Самаркандский Государственный медицинский институт, г. Самарканд, Республика Узбекистан
}

Неврологические расстройства в консенсусе нутритивной недостаточности рассматриваются как гетерогенная группа расстройств, которые в первую очередь относятся к поражению центральной нервной системы, влияющему на двигательные навыки, индивидуальную речь, зрение, память и когнитивные способности [13]. Во всем мире детский церебральный паралич (ДЦП) является не только самым распространенным [1,9] и сложным заболеванием среди всех нейромоторных нарушений у детей [5], но и наиболее распространённой причиной физической инвалидности в детском возрасте [6-8,10,16,18-20], диагностируемой у каждого из 500 детей в развитых странах $[11,16]$ и приводящей более чем к 1 миллиону хронических пациентов в возрасте 21 года [4]. Частота ДЦП по данным различных авторов варьирует и составляет в среднем 22,5 на 1000 живорожденных $[1,3,4,6,8,12,14,16,17]$. К примеру, в Австралии согласно Квинслендскому регистру ежегодно рождается 80-120 детей с ДЦП [11]. 
Развитие и нутритивный статус детей и подростков с церебральным параличом были предметом многочисленных исследований за последние 50 лет (Tobis с соавт. 1961; Spender с соавт. 1989; Stevenson с соавт. 1994; Krick с соавт. 1996; Stevenson с соавт. 2006; Day с соавт. 2007). У детей с тяжелыми неврологическими нарушениями как недоедание, так и переедание являются основными проблемами здоровья. Это побуждает проводить исследования по оценке состояния питания у этой категории детей, в том числе на основании изучения антропометрических показателей [1].

Основная цель антропометрии при ДЦП - оценка и мониторинг развития. Рост и масса тела часто используются как маркеры здоровья и для оценки нутритивного статуса. Дополнительные антропометрические измерения, такие как толщина кожно-жировой складки дают больше информации о процессе развития ребенка [15]. Толщина кожно-жировой складки считается важным, неинвазивным и точным антропометрическим параметром оценивания регионального и общего содержания жира и по рекомендациям ESPGHAN (European Society of Gastroenterology, Hepatology and Nutrition) должна стать обычном компонентом оценки нутритивного статуса у детей с церебральным параличом [2, 13].

Цель: изучить нутритивный анамнез и оценить нутритивный статус при различных формах детского церебрального паралича методом калиперометрии.

Материалы и методы. Углубленное клиниконеврологическое обследование проведено у 65 детей с диагнозом детский церебральный паралич в возрасте от 3-х до 15 лет, составивших основную группу. Контрольную группу составили 30 неврологически здоровых детей, наблюдавшихся в семейных поликлиниках г. Самарканда по месту жительства. Группы наблюдения были сопоставимы по возрасту и полу. В возрастном составе основной группы превалировали дети в возрасте 7-9 лет - 30 человек $(46,1 \%)$, с 3 до 6 лет 15 человек $(23,1 \%), 10-15$ лет - 20 пациентов $(30,8 \%)$. В то время как в контрольной группе распределение детей по возрасту выглядело следующим образом: 3-6 лет - 20\%, 7-9 лет $-40 \%$ и $10-15$ лет $-40 \%$.

План обследования детей в обеих группах включал также оценку нутритивного статуса на основании измерения толщины кожно-жировых складок. Наряду с оценкой медицинского анамнеза, во всех случаях проводилась глубокая оценка и анализ нутритивного анамнеза. В зависимости от формы детского церебрального паралича дети основной группы были разделены на пять подгрупп: 67,7\% (44 наблюдения) всех случаев детского церебрального паралича составляли спастические формы, представленные 3 подгруппами: тетрапарез (I-я подгруппа) - 14 пациентов (21,5\%); спастическая диплегия (II-я подгруппа) - 15 случаев $(23,1 \%)$; односторонняя спастическая гемипаретическая форма диагностирована у 15 больных (III-я подгруппа, 23,1\%). B IV-ю подгруппу вошли больные с гиперкинетической формой заболевания (11 наблюдений, 16,9\%). В V-ю подгруппу вошли 10 пациентов $(15,4 \%)$ с различной степенью выраженности статической и динамической атаксии.

Результаты. При анализе нутритивного анамнеза обследованных пациентов с детским церебральным параличом родители обращали внимание на трудности, возникающие при кормлении данной категории детей. Уже с момента рождения практически у всех пациентов основной группы возникали признаки орально-моторной дисфункции различной степени выраженности. Проблемы с сосанием выявлены у 100\% пациентов с тетрапарезом $(\mathrm{n}=14)$, несколько реже отмечались при гиперкинетической и атонически-астатической формах, составляя $81,8 \% \quad(n=9)$ и $90 \% \quad(n=9)$ соответственно. В среднем по группам больных с детским церебральным параличом в зависимости от преобладающих двигательных нарушений орально-моторная дисфункция с жалобами родителей на проблемы с глотанием, питьем, проблемы с введением твердой пищи, затруднения при откусывании, першение и кашель во время кормления и другие симптомы чаще диагностированы в I-ой подгруппе пациентов, составляя 88,8\%, несколько реже в IV-ой $(72,7 \%)$ и V-ой $(71,4 \%)$ подгруппах. У детей при спастической и гемипаретической формах церебрального паралича данные симптомы выявлены соответственно лишь в 45,7\% и $37,1 \%$ наблюдений. Для сравнения в контрольной группе неврологически здоровых детей признаки нарушения глотания в процессе кормления, являющиеся проявлением орально-моторной дисфункции, выявлены лишь в 4,3\% случаев.

На вопросы «Имеет ли у ребенка место плохая координация рука/рот, ведущая к потере пищи» или «Ребенок самостоятельно не ест» родители детей основной группы (анализ проводился среди детей возрастной категории старше 5 лет, $\mathrm{n}=47)$ в $22(46,8 \%)$ случаях подчеркнули, что ребенок самостоятельно не ест; у 15 пациентов $(31,9 \%)$ имела место плохая координация рука/рот, ведущая к потере пищи; а в 10 (21,3\%) случаях проблем с потреблением пищи у ребенка не возникало. Таким образом, проблемы с потреблением пищи имели место у 78,7\% пациентов основной группы. При этом у 32 $(68,1 \%)$ обследованных детей имело место нарушение естественной регуляции питания из-за коммуникативных трудностей, поскольку больной не мог четко дать знать о своем голоде, сытости, а также вкусовых предпочтениях.

Результаты изучения орально-моторной функции $(\mathrm{n}=65)$ у детей с церебральным параличом указывали на задержку развития возрастных оральных навыков (40; $61,5 \%)$; задержку реализации глотательного рефлекса, являющуюся наиболее частой причиной аспирации (34; 52,3\%); затрудненное закрывание рта (46; 70,8\%); слюнотечение $(38 ; 58,5 \%)$; постоянное выдвижение языка, вызывающее утечку пищи $(45 ; 69,2 \%)$; затрудненное формирование пищевого комка вследствие плохой координации произвольных движений мышц языка $(42 ; 64,6 \%)$.

С общими периферическими запасами белка и жировыми запасами организма с достаточно высокой точностью коррелирует толщина кожно-жировой складки 
над трицепсом. Измерение толщины кожно-жировой складки над трицепсом (мм) проводилось на уровне средней трети плеча электронным калипером по стандартной методике. Результаты затем оценивались по перцентильным таблицам: отсутствие нарушений питания (26-й - 75-й перцентиль) - 0 баллов; легкое нарушение питания (25-й - 10-й перцентиль) - 1 балл; умеренное снижение питания (9-й - 5-й перцентиль) - 2 балла; выраженное снижение питания (ниже 5 перцентиля) 3 балла. В результате интерпретации полученных данных выявлено, что отсутствие нарушений питания отмечено лишь у 20\% (13 наблюдений) детей с церебральным параличом и в 96,7\% случаев в контрольной группе. Легкое нарушение питания (25-й - 10-й перцентиль) диагностировано в 41,5\% наблюдений основной группы. Несомненно, интересен факт преобладания умеренного и выраженного нарушения питания у детей с церебральным параличом (23,1\% и 15,4\% соответственно). Средний балл при измерении толщины кожно-жировой складки над трицепсом в группе детей церебральным параличом составил 2,06 $\pm 0,29$ баллов, а у неврологически здоровых детей $0,34 \pm 0,36$ баллов.

И поскольку, выраженность орально-моторной дисфункции коррелирует с тяжестью заболевания и задержкой моторного развития в ходе исследования было выявлено, что для детей с тяжелыми двигательными нарушениями характерны тяжелые формы нутритивной недостаточности, коррелирующие с толщиной кожножировой складки над трицепсом. В целом $80 \%$ обследованных детей с церебральным параличом имели ту или иную степень нутритивной недостаточности, возникающей вследствие проблем с питанием.

Выводы. Таким образом, для определения степени дефицита питания у детей с детским церебральным параличом должно проводиться комплексное исследование, включающее в себя определение не только клинико-неврологических показателей, но и антропометрических параметров. Оценка антропометрических показателей у детей с церебральным параличом является важным и доступным инструментом диагностики недостаточности питания.

Поскольку причины нутритивной недостаточности при детском церебральном параличе обусловлены рядом факторов, напрямую связанных с нарушением нервной регуляции, основными причинами которых является повреждение мозговых центров, а также нарушение глотательной и жевательной функций, необходим тщательный мониторинг нутритивного анамнеза и статуса, разработка рациона с назначением нутритивной поддержки по показаниям и ее обязательной коррекцией с учетом возраста, характера течения основного заболевания, наличия сопутствующей патологии, а также объема и интенсивности реабилитационных/ абилитационных мероприятий.

Ключевые слова: детский церебральный паралич, нутритивный статус, калиперометрия, толщина кожножировых складок, антропометрия.

\section{Литература}

1. Adamu Sa'idu Adamu, Umar Abba Sabo, Garba Dayyabu Gwarzo, Raymond O. Belonwu. Nutritional status in cerebral palsy: A Cross-sectional comparative survey of children in Kano, Nigeria. Niger Postgrad Med J. 2018 Jul-Sep; 25(3):156-160. doi: 10.4103/npmj.npmj_67_18.

2. Addo O. Y., Himes J. H. Reference curves for triceps and subscapular skinfold thicknesses in US children and adolescents. Am J Clin Nutr. 2010. № 91. P. 635- 642. doi: 10.3945/ajcn.2009.28385.

3. Arghavan Shariat, Ardalan Shariat, Ahmad Abedi, Shamsul Bahri Mohd Tamrin. Physical activity as a prescription for the children with cerebral palsy // Russian Open Medical Journal 2014; 3: 0108.

4. Chernykh ER, Kafanova MYu, Shevela EYa, Adonina EI, Sakhno LV, Tikhonova MA, Ostanin AA. Autologous M2-like macrophage applications in children with cerebral palsy. Cell Ther Transplant. 2011; 3:e.000092.01. doi:10.3205/ ctt-2011-en-000092.01.

5. Cosmina Stănoiu. Clinical and functional aspects of evaluation and rehabilitation of spastic upper limb in children with infantile cerebral palsy. - Craiova 2012. - P. 150.

6. Erasmus C. E., van Hulst K., Rotteveel J. J. et al. Clinical practice: swallowing problems in cerebral palsy // Eur. J. Pediatr. 2012. Vol. 171 (3): 409-414.

7. Farhoud Saeid Ershadi, Golamreza Aminian, Mehdi Rassafiani, Monireh Ahmadi Bani. The Effect of gait training with Hip Orthosis on Gait Parameters in a Cerebral Palsy Crouch Gait: a case study // International Journal of Advanced Biotechnology and Research (IJBR), Vol-7, Special Issue-Number 2-April, 2016, pp1419-1425.

8. Figueroa M. J., Rojas C., Barja S. Morbimortality associated to nutritional status and feeding path in children with cerebral palsy // Chil Pediatr. 2017. № 88 (4). P. 478-486.

9. García Iñiguez J.A., Vásquez-Garibay E.M., García Contreras A., Romero-Velarde E., Troyo Sanromán R. Assessment of anthropometric indicators in children with cerebral palsy according to the type of motor dysfunction and reference standard. Nutr Hosp 2017; 34(2): 315-322. DOI: 10.20960/ nh.353.

10. Herrera-Anaya E., Angarita-Fonseca A., Herrera-Galindo V. M. et al. Association between gross motor function and nutritional status in children with cerebral palsy: a cross-sectional study from Colombia // Dev. Med. Child Neurol. 2016. 58 (9): 936-941. 
11. Kristie L Bell, Roslyn N Boyd, Sean M Tweedy, Kelly A Weir, Richard D Stevenson, Peter SW Davies A prospective, longitudinal study of growth, nutricion and sedentary behavior in young children with cerebral palsy // Public Health 2010, 10:179.

12. Peter L. Rosenbaum, Stephen D. Walter, Steven E. Hanna, Robert J. Palisano, Dianne J. Russell, Ellen Wood, Doreen J. Bartlett, Barbara E. Galuppi. Prognosis for Gross Motor Function in Cerebral Palsy Creation of Motor Development Curves // JAMA. 2002; 288(11): 1357-1363 (DOI: 10.1001/jama.288.11.1357).

13. Romano C., van Wynckel M., Hulst J., Broekaert I., Bronsky J., Dall'Oglio L. et al. European Society for Paediatric Gastroenterology, Hepatology and Nutrition Guidelines for the Evaluation and Treatment of Gastrointestinal and Nutritional Complications in Children With Neurological Impairment. J Pediatr Gastroenterol Nutr 2017; 65: 242-264. DOI: 10.1097/ MPG.0000000000001646.

14. Steven E Hanna, Doreen J Bartlett, Lisa M Rivard, Dianne J Russell. Reference urves for the Gross Motor Function Measure: Percentiles for Clinical Description and Tracking Over Time Among Children With Cerebral // Palsy Physical Therapy. Volume 88. Number 5. May 2008: 596-607.

15. Toivo Jürimäe, Jaak Jürimäe. Growth, physical activity, and motor development in prepubertal children. CRC Press. Boca Raton London New York Washington, D.C. 2000. P. 201.

16. Christine Imms, Iona Novak, Claire Kerr, Melinda Randall, Adrienne Harvey, H Kerr Graham, Dirah Reddihough. Improving allied health professionals' research implementation behaviours for children with cerebral palsy: protocol for a beforeafter study // Implementation Science, 2015, 10:16 DOI 10.1186/s13012-014-0202-0.

17. Morag J Andrew, Jeremy R Parr, Chris Montague-Johnson, Oliver Braddick, Karen Laler, Nicola Williams, Bonny Baker, Peter Sullivan Optimising nutrition to improve growth and reduce neurodisabilities in neonates at risk of neurological impairment, and children with suspected or confirmed cerebral palsy // BMC Pediatrics, 2015. 15:22.

18. Patrick G. McPhee, Joyce L Benner, Astrid C.J. Balemans, Olaf Verschuren, Rita J.G van den Berg-Emons, Edvard A. Hurvitz, Mark D. Peterson, Wilma M.A van der Slot, Marij E. Roebroeck, Jan Willem Gorter Multimorbidity risk assessment in adolescents and adults with cerebral palsy: a protocol for establishing a core outcome set for clinical research and practice // Trials (2019) 20:176 doi.org/10.1186/s13063-019-3265-z.

19. Rosalie Power, Rahena Akhter, Mohammad Muhit, Sabrina Wadud, Eamin Heanoy, Tasnnem Karim, Nadia Badaw, Gulam Khandaker A quality of life questionnaire for adolescents with cerebral palsy: psychometric properties of the Bengali CPQoL-teens // Health and Quality of Life Outcomes, 2019, 17:135 doi.org/10.1186/s12955-019-1206-X.

20. Eun-Young Park Relationship between activity limitation and health-related quality of life in school-aged children with cerebral palsy: a cross-sectional study // Health and Quality of Life Outcomes, 2017, 15:87 DOI 10.1186/s12955-017-0650-8.

Умирова С.М., Сабирова Ш.Б.

\title{
Применение нейропротекторов в восстановлении двигательных функций у больных после ишемического инсульта
}

\begin{abstract}
Самаркандский Государственный медицинский институт, кафедра медицинской реабилитации, спортивной медицины и народной медицины, г. Самарканд, Республика Узбекистан
\end{abstract}

Ишемический инсульт - это острая недостаточность мозгового кровообращения, влекущая за собой нарушения неврологических функций. Острый ишемический инсульт возникает из-за закупорки сосуда тромбом, или эмболом. Из-за нарушенного кровообращения участки головного мозга гибнут, а те функции, которые они контролировали, нарушаются. Более $50 \%$ больных, перенесших инсульт, имеют двигательные нарушения различной степени выраженности, 30\% становятся тяжелыми инвалидами и не могут передвигаться без посторонней помощи.

Цель - изучение эффективности применения Церабин-Ц в терапии двигательных нарушений после ИИ.
Материалы и методы. В исследование были включены 60 больных с ИИ, 35 мужчин и 25 женщина, в возрасте от 40 до 75 лет. Критериями включения больных в исследование были: инфаркт в левом полушарии большого мозга с развитием гемипареза разной степени выраженности и нарушений походки; острый (5-16-е) сутки и ранний восстановительный (1-2 мес.) периоды инсульта. Локализация и характер очаговых изменений мозга подтверждались данными рентгеновской компьютерной (КТ) или магнитно-резонансной (МРТ) томографии головного мозга. Инфаркты мозга локализовались в левом полушарии большого мозга в бассейне средней мозговой артерии. Выраженность неврологических нарушений оценивалась по шкале 